\title{
Fourfold Pattern of Undertaking Risky Environmental Projects
}

\author{
Mike Fung
}

\begin{abstract}
Majority of past studies on managerial risk-taking have examined the determinants of risk-taking from the agency perspective. However, a substantial body of evidence has shown that Expected Utility Theory (EUT) provides inadequate description for decision-making under risky prospects. This study proposes an empirical framework for investigating managerial incentives to undertake risky environmental projects. Such incentives are assumed to follow the fourfold pattern of risk-attitude as implied by Cumulative Prospect Theory (CPT) - risk-taking is higher over low-probability reference gains or high-probability reference losses, and is lower over high-probability reference gains or low-probability reference losses. Reference gains and losses are respectively defined as positive and negative deviations from peers' performance.
\end{abstract}

Keywords: Managerial risk-taking; Environmental projects; Prospect theory.

Mike Fung

Faculty of Business

Hong Kong Polytechnic University

Hong Kong 